Check for updates

Cite this: RSC Adv., 2019, 9, 166

Received 17th October 2018

Accepted 11th December 2018

DOI: $10.1039 / \mathrm{c} 8 \mathrm{ra0} 0584 \mathrm{f}$

rsc.li/rsc-advances

\section{Light-triggered hydrophilic drug release from liposomes through removal of a photolabile protecting group $\uparrow$}

\author{
Yuya Goto, ${ }^{a}$ Masafumi Ueda, ${ }^{\text {ab }}$ Kouta Sugikawa, (D) ${ }^{a}$ Kazuma Yasuharac \\ and Atsushi Ikeda iD *a
}

The antibiotic penicillin G cannot be completely incorporated into hydrophobic lipid-membranes owing to its hydrophilicity. Through modification with a hydrophobic and photolabile protecting group, penicillin $G$ was effectively incorporated into liposomes and released by photoirradiation at $365 \mathrm{~nm}$.

\section{Introduction}

The ability to regulate the release of an appropriate dose of drug at a specific location with the correct timing is very important for liposomal drug-delivery systems used in selective tissue targeting. ${ }^{1-5}$ Drug release can be controlled by $\mathrm{pH}$, thermal, enzymatic, or photochemical triggers. Many research groups have reported liposomal drug-delivery systems that use the liposome collapse or the considerable distortion of the membrane that results from these triggers to affect release.$^{\mathbf{6 - 1 0}}$ In contrast, several groups have reported drug-delivery systems that use the introduction and elimination of a guest molecule protecting group to control release. For example, hydrophilic guest molecules can be incorporated into hydrophobic lipid membranes using hydrophobic protecting groups. In lipid membrane-incorporated guest molecules (LMIGs), the incorporation or leakage percentages of guest molecules are predicted by the hydrophobicity of the guest molecules. Schwarzenbach et al. directly determined the liposome-water distribution ratio $\left(\log K_{\text {lipw }}\right)$ of phenols and phenoxides and reported that the $\log K_{\text {lipw }}$ values of phenols are very similar to the octanol-water partition coefficient $\left(\log P_{\text {ow }}\right) .^{11-13}$ In contrast, we investigated the relationship between the equilibrium and the $\log P_{\text {ow }}$ for some small model guest molecules with a $\pi$-moiety. ${ }^{14}$ Our results indicated that many of the guest molecules with $\log P_{\text {ow }}<1.9$ leaked from the lipid membranes, while most of the guest molecules with $\log P_{\mathrm{ow}}>1.9$ did not. That is, the threshold for leakage of guest

${ }^{a}$ Department of Applied Chemistry, Graduate School of Engineering, Hiroshima University, 1-4-1 Kagamiyama, Higashi-Hiroshima 739-8527, Japan

${ }^{b}$ School of Science, Kitasato University, 1-15-1 Kitasato, Minami-ku, Sagamihara, Kanagawa 252-0373, Japan

${ }^{c}$ Graduate School of Materials Science, Nara Institute of Science and Technology, 89165 Takayama, Ikoma, Nara 630-0192, Japan

$\dagger$ Electronic supplementary information (ESI) available: Experimental procedures, ${ }^{1} \mathrm{H}$ NMR, MS/MS and UV-vis absorption spectra. See DOI: 10.1039/c8ra08584f molecules was determined to be $\log P_{\text {ow }} \approx 1.9 .^{14}$ Therefore, if the $\log P_{\text {ow }}$ of the guest molecules can be controlled, the amount of drug released can be varied. For example, a dimer of a coumarin derivative $\left(\log P_{\mathrm{ow}}>3\right.$ ) was reverted to monomers in the lipid membrane by photoirradiation at $254 \mathrm{~nm}$ and the monomer $\left(\log P_{\text {ow }}=1.78\right)$ was released.${ }^{15}$ In this work, we used penicillin $\mathrm{G}(\mathbf{1})^{\mathbf{1 6 , 1 7}}\left(\log P_{\mathrm{ow}}=1.85\right)^{\mathbf{1 8}}$ as an example of a hydrophilic drug. We report the synthesis of 1 protected with the hydrophobic photolabile protecting group 2-nitro-3naphthalenemethanol (NNM) ${ }^{19-21}$ (Scheme 1), and the release of the penicillin $\mathrm{G}$ from liposomes by photocleavage of the protecting group (Scheme 2).

(a)
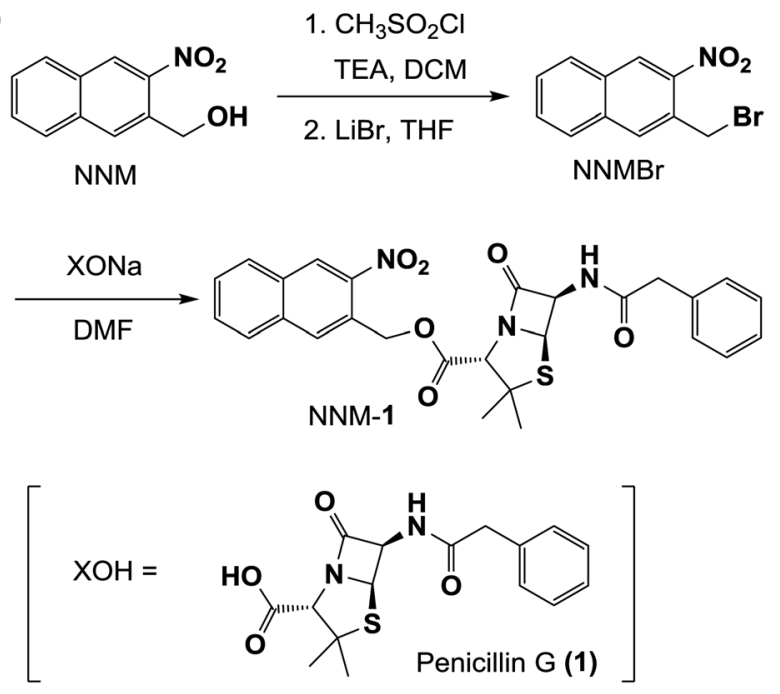

(b)

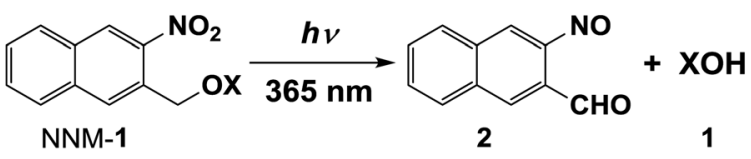

Scheme 1 (a) Synthesis of NNM-1 and (b) photocleavage of NNM-1. 


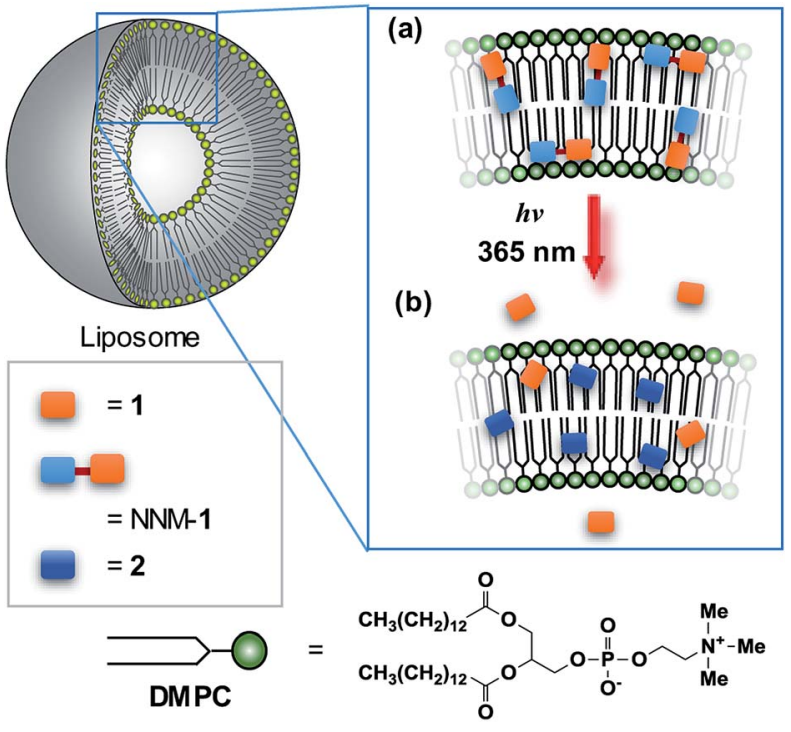

Scheme 2 Schematic illustration of (a) NNM-1 with a conjugated photolabile protecting group inside the lipid membrane and (b) 1 outside the lipid membrane as a result of photocleavage of the protecting group through photoirradiation at $365 \mathrm{~nm}$, and the structure of DMPC.

\section{Results and discussion}

Photocleavage of the protecting group in NNM-1 in DMSO

To confirm the photocleavage of the protecting group in NNM-1 $\left(\log P_{\text {ow }}=4.13\right),{ }^{13}$ we measured the ${ }^{1} \mathrm{H}$ NMR and UV-vis absorption spectra of NNM-1 in DMSO after photoirradiation at $365 \mathrm{~nm}$ for $24 \mathrm{~h}$. As shown in Fig. 1 and S2, $\dagger$ NNM moiety ${ }^{1} \mathrm{H}$ NMR peaks in NNM-1 (Fig. 1b; blue circles) were no longer detected after photoirradiation at $365 \mathrm{~nm}$, and new peaks appeared (Fig. 1c). Because these peaks (Fig. 1c; red circles) are similar to those of the sodium salt of $\mathbf{1}$ (Fig. 1a; red circles), the photocleavage of NNM-1 and generation of $\mathbf{1}$ were suggested as shown in Scheme $1 \mathrm{~b}$. Because of the disagreement in the chemical shifts of the ${ }^{1} \mathrm{H}$ NMR peaks in Fig. 1a and c, we attempted to prepare $\mathbf{1}$. However, $\mathbf{1}$ decomposed when treated with an $\mathrm{HCl}$ solution, as it is unstable in acidic conditions. ${ }^{22}$

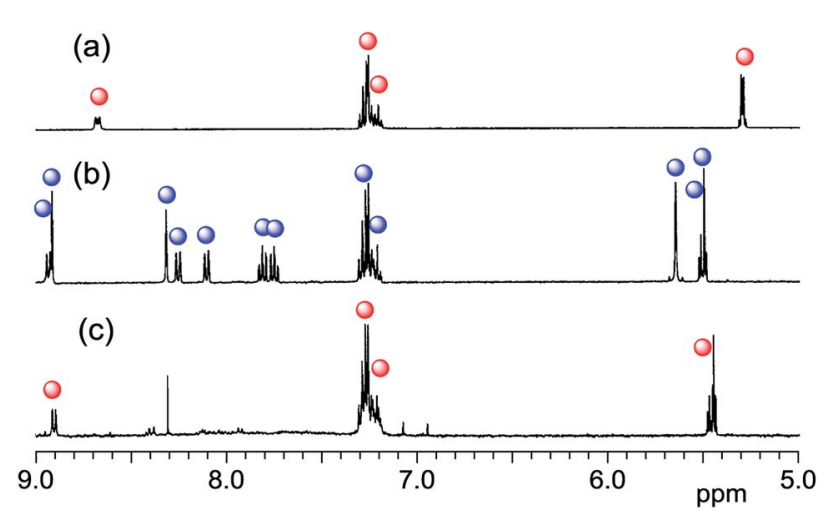

Fig. 1 Partial ${ }^{1} \mathrm{H}$ NMR spectra $\left(400 \mathrm{MHz}, \mathrm{DMSO}-d_{6}, 25^{\circ} \mathrm{C}\right)$ of (a) sodium salt of 1 and (b and c) NNM-1 (b) before and (c) after photoirradiation at $365 \mathrm{~nm}$ for $24 \mathrm{~h}$ (red circles: 1, blue circles: NNM-1).
To confirm the generation of $\mathbf{1}$, we measured the electrospray ionisation mass spectroscopy (ESI-MS) (Fig. 2). Before photoirradiation, 1 was not observed in the ESI-MS spectrum of NNM1 as a fragment (Fig. 2a). An ambiguous ion at $m / z 345.09$ was found to be a fragment of NNM-1 because the same peak was observed as a product ion of $\mathrm{m} / \mathrm{z} 520$ in the ESI-MS/MS for fragments generated by collision induced dissociation (Fig. S3†). However, only trace amounts of ions of 1 were observed in the sample of NNM-1 before the photoirradiation at $365 \mathrm{~nm}$. In contrast, after photoirradiation, ions of 1 were detected in both the positive and negative modes, while only

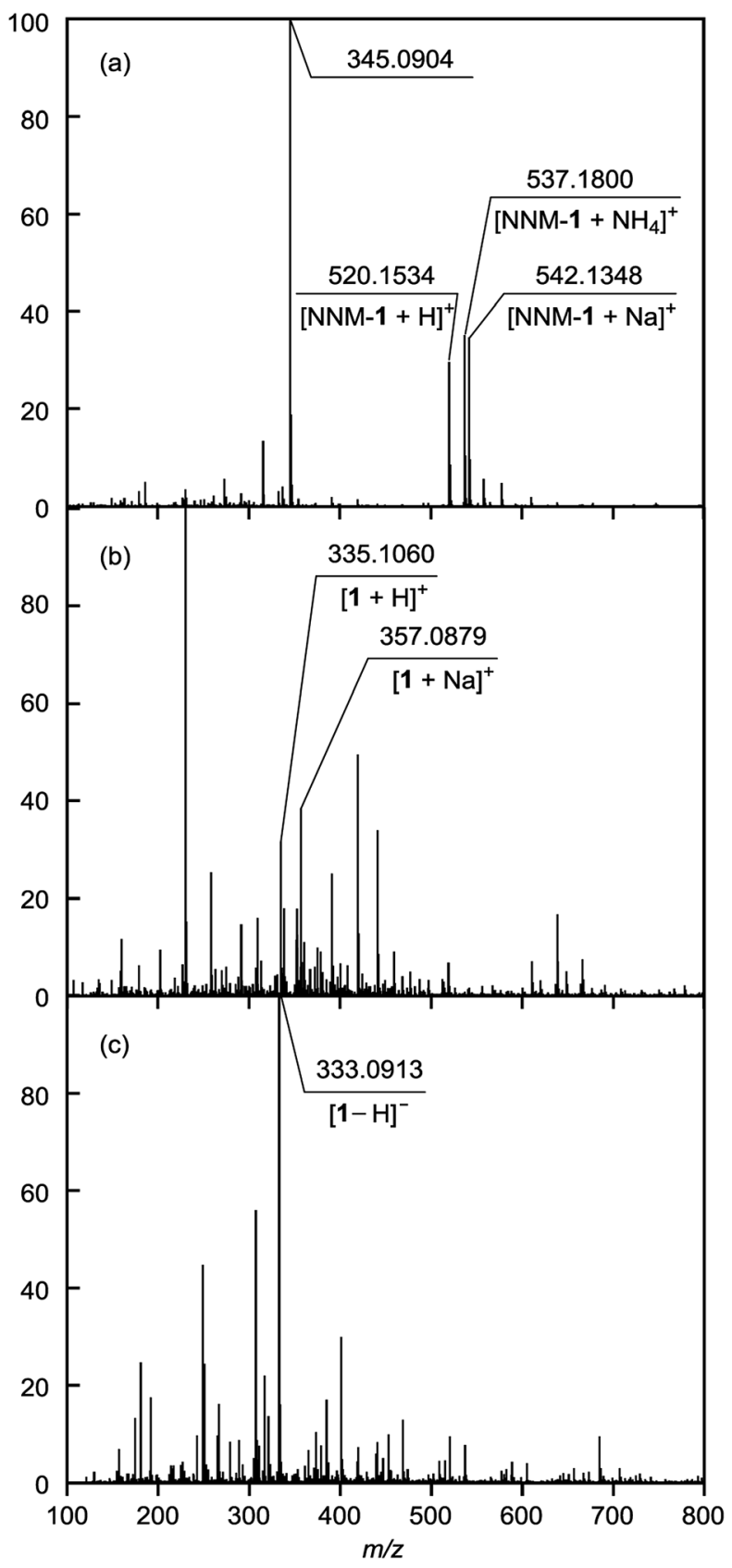

Fig. 2 ESI-MS spectra of NNM-1 (a) before (positive ion mode), (b) after (positive ion mode), and (c) after (negative ion mode) photoirradiation at $365 \mathrm{~nm}$ for $24 \mathrm{~h}$ in $\mathrm{CHCl}_{3}$. 


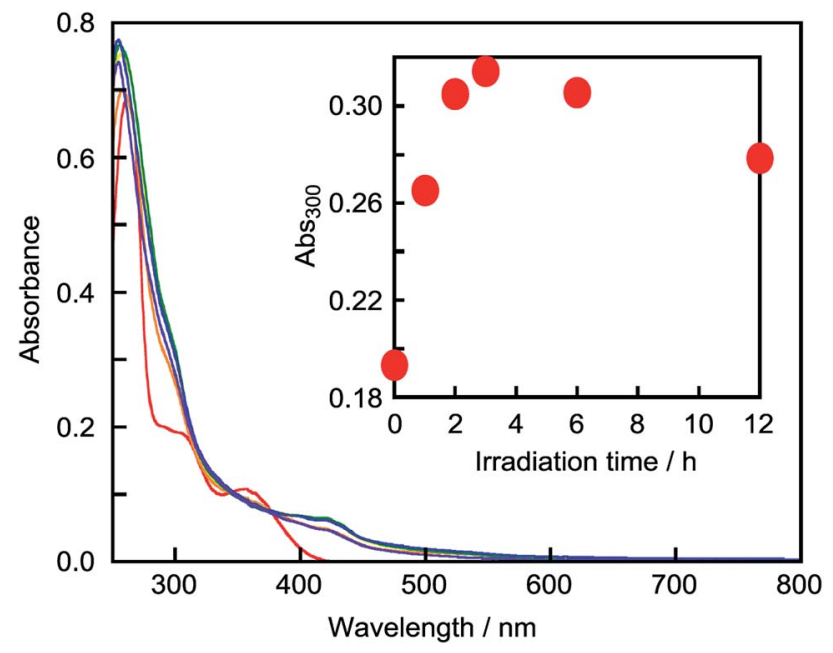

Fig. 3 Time-dependent UV-vis spectral changes of NNM-1 (inset: incubation time-dependence of the absorbance at $410 \mathrm{~nm}$ ) upon photoirradiation at $365 \mathrm{~nm}\left(1.1 \mathrm{~mW} \mathrm{~cm}{ }^{-2}\right)$ for 0 (red line), 1 (orange line), 2 (yellow line), 3 (green line), 6 (blue line) and 12 (purple line) $\mathrm{h}$ $([\mathrm{NNM}-1]=0.40 \mathrm{mM})$

trace amounts of ions of NNM-1 were observed (Fig. 2c). These results clearly show that NNM-1 was almost completely cleaved after the photoirradiation. Therefore, the disagreement in the ${ }^{1} \mathrm{H}$ NMR peaks between Fig. 1a and c, is thought to arise from Fig. 1a showing the spectrum of the sodium salt of 1 .

As shown in Fig. 3, the UV-vis absorption of NNM-1 changed after photoirradiation at $365 \mathrm{~nm}$ in DMSO. The spectrum after $12 \mathrm{~h}$ was similar to that of the sodium salt of $\mathbf{1}$ in $\mathrm{H}_{2} \mathrm{O}$ (Fig. S4†), and was consistent with a previous result. The absorption changes of NNM-1 were saturated after $12 \mathrm{~h}$ of photoirradiation. However, the absorbance decreased after $3 \mathrm{~h}$ of photoirradiation. This result suggests that compound 1 decomposed, and the emergence of peaks of some degradation products supported this. The structures of the degradation products could not be determined as they were only produced in small amounts.

\section{Determination of leakage percentages of 1 and NNM-1 from liposomes}

Lipid membrane-incorporated 1 and NNM-1 (LMI1 and LMINNM-1, respectively) were prepared using 1,2-dimyristoyl-snglycero-3-phosphocholine (DMPC, Scheme 2) and a premixing method (Scheme S1†). ${ }^{15,23,24}$ LMI1 and LMI-NNM-1 were obtained by dissolving DMPC and the guest molecules ( 1 or NNM-1) in chloroform, followed by concentration of the resulting mixture to give a residue that was extracted with water. Because compound $\mathbf{1}$ does not precipitate at this concentration, all 1 present existed either in the lipid membrane or in bulk solution. Therefore, the leakage percentage of 1 from liposomes was calculated to be $82 \%$, based on the ${ }^{1} \mathrm{H}$ NMR spectrum, which indicated that $18 \%$ of 1 was residual in the lipid membrane ([1]/[DMPC $]=10 \mathrm{~mol} \%)$. The leakage of $1\left(\log P_{\mathrm{ow}}=1.85\right)$ is consistent with previous findings that many guest molecules with $\log P_{\text {ow }}<1.9$ leak
Table 1 Average hydrodynamic diameters $\left(D_{\text {hy, }} n\right.$ m) of LMI-NNM-1 before and after photoirradiation determined by dynamic light scattering at $25^{\circ} \mathrm{C}$

\begin{tabular}{llc}
\hline & Average $D_{\mathrm{hy}} / \mathrm{nm}$ & $\mathrm{PDI}^{a}$ \\
\hline Before photoirradiation & 66.3 & 0.103 \\
After photoirradiation & 68.3 & 0.087 \\
${ }^{a}$ PDI: polydispersity index. & &
\end{tabular}

from lipid membranes. ${ }^{14}$ In contrast, NNM-1 which leaked out of the liposomes, precipitated as a result of being insoluble in water. To determine the concentration of NNM-1 in LMI-NNM$\mathbf{1}$, the residue was dissolved in $\mathrm{CDCl}_{3}$ containing ethanol $(0.4$ $\mathrm{mM}$ ) as an internal standard, to measure the ${ }^{1} \mathrm{H}$ NMR spectrum after lyophilisation of the LMI-NNM-1 solution (Fig. S5 $\dagger$ ). From the peak intensities, [NNM-1]/[DMPC] was calculated to be $3.4 \mathrm{~mol} \%$. Because the initial ratio of [NNM-1]/[DMPC] was $10 \mathrm{~mol} \%$, the residual NNM-1 $([\mathrm{NNM}-1] /[\mathrm{DMPC}]=6.6 \mathrm{~mol} \%)$ was not incorporated into the liposomes and precipitated. The precipitate was removed from the aqueous solution by filtration to give LMI-NNM-1. The incorporation of a high proportion of NNM-1 in the lipid membrane was a result of the hydrophobicity of NNM-1 $\left(\log P_{\text {ow }}=4.13\right) \cdot{ }^{14}$ The average hydrodynamic diameter $\left(D_{\text {hy }}\right)$ of LMI-NNM-1 was almost unchanged following photoirradiation, suggesting that the liposome morphology did not change after the photocleavage of NNM-1 (Table 1).

\section{Photocleavage of the protecting group in NNM-1 in liposomes}

To determine the saturation time of photoirradiation, UV-vis absorption spectra were measured. The absorption of NNM-1 under both dark conditions and photoirradiation was measured for the LMI-NNM-1 solution (Fig. 4). Under dark conditions, the UV-vis absorption spectrum showed only marginal change (Fig. 4a). This result indicates that, (i) NNM-1 did not decompose in the absence of photoirradiation and (ii) the LMI-NNM-1 solution was stable for $1 \mathrm{~d}$. After photoirradiation, the absorption intensity decreased and then saturated after $12 \mathrm{~h}$. Peak broadening was observed in a similar manner to NNM-1 in DMSO (Fig. 3 and 4b). This result suggests that NNM-1 was almost completely photocleaved after $12 \mathrm{~h}$.

To confirm whether NNM-1 and cleaved $\mathbf{1}$ were present in the lipid membrane or bulk water, we measured the ${ }^{1} \mathrm{H}$ NMR spectra of LMI-NNM-1 after photoirradiation for $12 \mathrm{~h}$. The peak intensities in Fig. 5 and $56 \dagger$ were normalised relative to the value of DMSO $(0.4 \mathrm{mM})$ as an internal standard. The leakage percentage of 1 was found to be $74 \%$, based on the peak intensities of 1 relative to the DMSO peak. In contrast, no peaks were observed for the LMI-NNM-1 solution (Fig. 5b). It is well known that lipids peaks and those belonging to guest molecules are not detected for LMIGs as a consequence of peak broadening resulting from the formation of the liposomes. ${ }^{25-30}$ Therefore, the absence of peaks belonging to NNM-1 suggests that all of the NNM-1 was completely incorporated into the liposomes. 


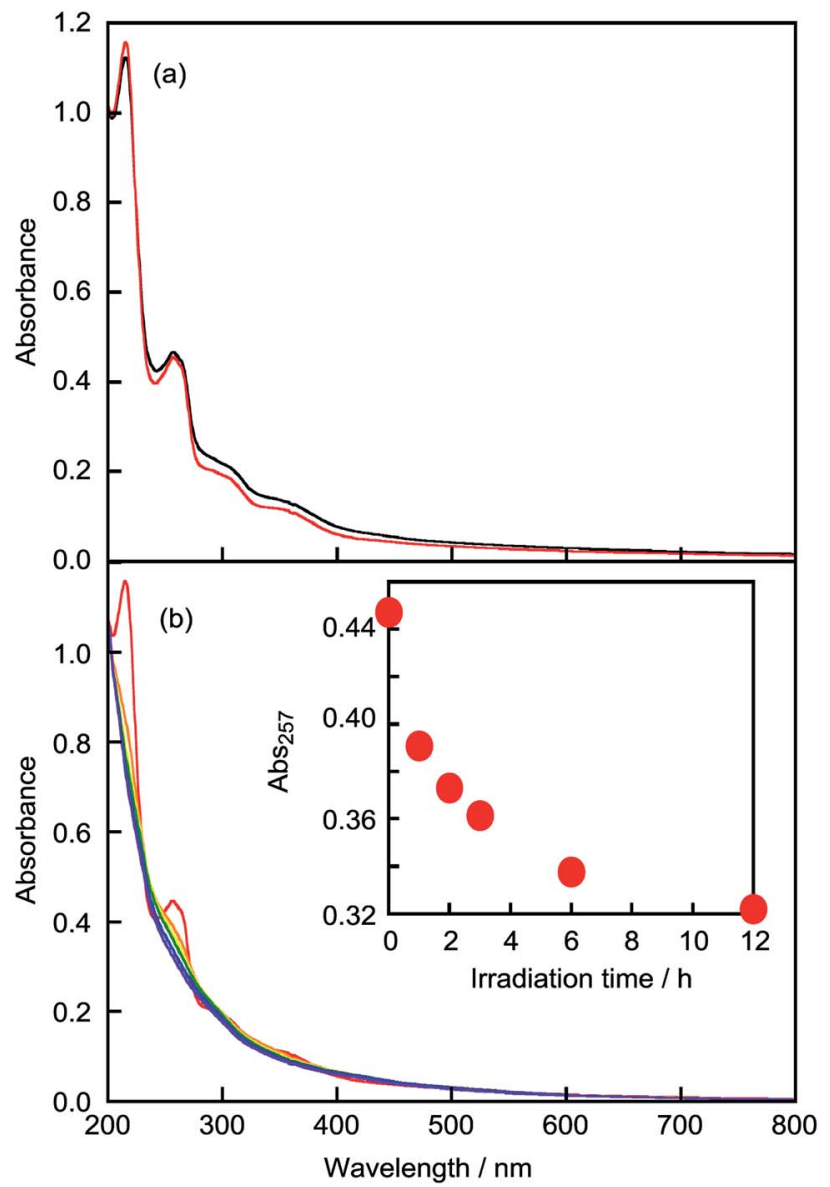

Fig. 4 Time-dependent UV-vis spectral changes of liposome-NNM-1 mixture (a) after 0 (black line) and $24 \mathrm{~h}$ (red line) incubation under dark conditions and (b) upon photoirradiation at $365 \mathrm{~nm}\left(1.1 \mathrm{~mW} \mathrm{~cm}{ }^{-2}\right)$ for 0 (red line), 1 (orange line), 2 (yellow line), 3 (green line), 6 (blue line) and 12 (purple line) $\mathrm{h}$ (inset: incubation time-dependence of the absorbance at $257 \mathrm{~nm}$ ).

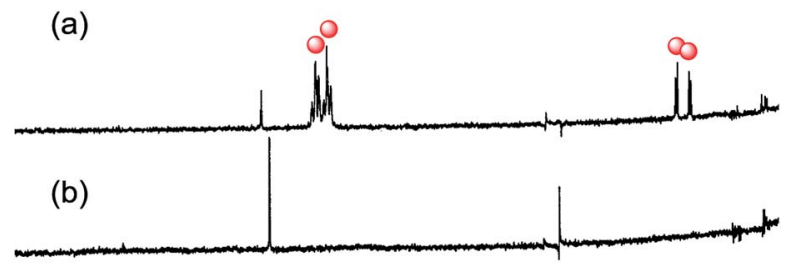

(c)

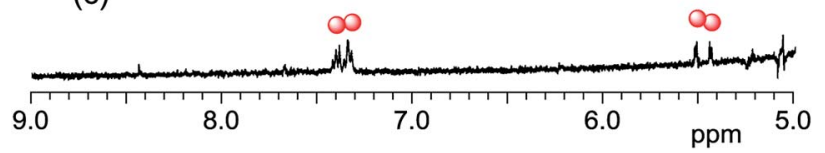

Fig. 5 Partial ${ }^{1} \mathrm{H}$ NMR spectra $\left(400 \mathrm{MHz}, \mathrm{D}_{2} \mathrm{O}, 25^{\circ} \mathrm{C}\right)$ of (a) liposomes1 mixture ([1]/[DMPC] $=10$ mol\%) and liposomes-NNM-1 mixture (b) before and (c) after photoirradiation at $365 \mathrm{~nm}$ for $12 \mathrm{~h}$ ([NNM-1]/ $[D M P C]=10$ mol\%), (red circles: 1 in bulk water).

\section{Antimicrobial activity of LMI-NNM-1 before and after photoirradiation}

We determined the antimicrobial activity of LMI-NNM-1 before and after photoirradiation toward Staphylococcus aureus ( $S$. aureus) ATCC 25923. The minimum inhibitory concentration (MIC) of LMI-NNM-1 after photoirradiation at $365 \mathrm{~nm}$ for $12 \mathrm{~h}$ $\left(0.23 \mu \mathrm{g} \mathrm{mL} \mathrm{mL}^{-1}\right)$ was much lower than that measured before photoirradiation $\left(>1.82 \mu \mathrm{g} \mathrm{mL} \mathrm{m}^{-1}\right)$. This indicates that the antimicrobial activity of LMI-NNM-1 after photoirradiation was higher than that before photoirradiation. Consequently, the penicillin G 1 released from the lipid membranes was able to function as an antimicrobial agent. However, the MIC value was higher than that of pristine penicillin G sodium salt $(0.03 \mu \mathrm{g}$ $\mathrm{mL}^{-1}$ ) because the leakage percentage of 1 was found to be $74 \%$, and 1 released to the inner aqueous phase of the vesicles did not act as an antimicrobial agent.

\section{Conclusions}

The leakage percentage of pristine penicillin G $1\left(\log P_{\mathrm{ow}}=1.85\right)$ from lipid membranes was found to be $82 \%$. In contrast, the majority of a sample of $\mathbf{1}$ was incorporated into the hydrophobic lipid membrane following modification with NNM as a hydrophobic protecting group. Consequently, the leakage of NNM-1 $\left(\log P_{\mathrm{ow}}=4.13\right)$ was minimal. After photoirradiation at $365 \mathrm{~nm}$, deprotected 1 was released from the lipid membrane and the leakage percentage from NNM-1 incorporated in the lipid membrane was $74 \%$. Because the leakage percentage of 1 from the liposomes was $82 \%$, the release of $\mathbf{1}$ by photoirradiation was considered to have proceeded efficiently.

\section{Experimental}

\section{Materials}

Penicillin G sodium salt and 1,2-dimyristoyl-sn-glycero-3-phosphocholine (DMPC) were purchased from Tokyo Chemical Industry Co., Ltd. (Tokyo, Japan) and Funakoshi Co., Ltd (Tokyo, Japan), respectively. $\mathrm{NNM}^{19}$ was synthesized according to previously reported methods.

\section{Synthesis of NNMBr}

A solution of NNM $(100.0 \mathrm{mg}, 0.49 \mathrm{mmol})$ in dichloromethane $(5 \mathrm{~mL})$ was added to triethylamine $(101.2 \mathrm{mg}, 1.00 \mathrm{mmol})$ and methylsulfonyl chloride $(85.9 \mathrm{mg}, 0.75 \mathrm{mmol})$ in an ice bath. The reaction mixture was then stirred in the ice bath for $30 \mathrm{~min}$. After $30 \mathrm{~min}$, the reaction mixture was extracted with dichloromethane and washed with saturated sodium hydrogen carbonate solution and saturated sodium chloride solution. The organic layer was then dried with $\mathrm{MgSO}_{4}$ and filtered. After evaporating in vacuo, the crude product was dissolved in THF (5 $\mathrm{mL}$ ) and lithium bromide (338 $\mathrm{mg}, 3.9 \mathrm{mmol}$ ) was added. The reaction mixture was stirred at room temperature for $16 \mathrm{~h}$. After evaporating in vacuo, the crude product was extracted with dichloromethane and washed with saturated sodium hydrogen carbonate solution and saturated sodium chloride solution. The organic layer was dried with $\mathrm{MgSO}_{4}$ and filtered. The product was dried under vacuum. Yellow solid, $55.3 \mathrm{mg}(42 \%) .{ }^{1} \mathrm{H}$ NMR $\left(400 \mathrm{MHz}, \mathrm{CDCl}_{3}\right) \delta 8.65(\mathrm{~s}, 1 \mathrm{H}), 8.01-7.90(\mathrm{~m}, 3 \mathrm{H}), 7.71-7.65(\mathrm{tt}$, $J=4.6 \mathrm{~Hz}, 2 \mathrm{H}) 5.04(\mathrm{~s}, 2 \mathrm{H}) \mathrm{ppm}$. 
Preparation of lipid-membrane-incorporated 1 and NNM-1 using the premixing method

An appropriate amount of a mixture of DMPC $(6.00 \mu \mathrm{mol})$ and 1 or NNM-1 ([DMPC] : [1 or NNM-1] = $10: 1 \mathrm{~mol} \mathrm{~mol}^{-1}$ ) was dissolved in chloroform. The solvent was evaporated under a gentle stream of nitrogen, followed by a period under vacuum to remove trace solvent. The resulting thin lipid films were hydrated on the wall of the vial above the phase transition temperature with an appropriate amount of water or $\mathrm{D}_{2} \mathrm{O}(1.5$ $\mathrm{mL})$. The hydrated materials were subjected to eight freezethaw cycles $\left(-195\right.$ and $\left.+50{ }^{\circ} \mathrm{C}\right)$ to give unilamellar vesicles, which were extruded 11 times through $0.05 \mu \mathrm{m}$ pores using a LiposoFast ${ }^{\mathrm{TM}}$ Mini-extruder (Avestin, Ottawa, ON, USA) above the phase transition temperature.

\section{Photoirradiation of NNM-1 and LMI-NNM-1 solutions at 365 nm}

A solution of NNM-1 in DMSO or LMI-NNM-1 in water was photoirradiated at $365 \mathrm{~nm}$ in a $1 \mathrm{~mm}$ quartz cell $\left(1.1 \mathrm{~mW} \mathrm{~cm}^{-2}\right)$. The photoreactions were monitored by UV-vis absorption and ${ }^{1} \mathrm{H}$ NMR spectroscopies. The photocleavage of NNM-1 was confirmed by MS and ${ }^{1} \mathrm{H}$ NMR spectra.

\section{Determination of the leakage percentages of guest molecules by ${ }^{1} \mathrm{H}$ NMR spectroscopy}

DMSO $(0.4 \mathrm{mM})$ was added to aqueous solutions of LMIGs as an internal standard. The leakage percentages were determined by comparing the peak intensity of the guest molecules with that of DMSO.

\section{Dynamic light scattering (DLS) analysis}

The hydrodynamic diameters and the zeta potentials of the liposomes were measured on an electrophoretic light scattering instrument equipped with a laser Doppler system (Zetasizer Nano ZS, Malvern Instruments Ltd, Malvern, UK).

\section{Determination of antimicrobial activity}

Antimicrobial activity was evaluated by finding the minimum inhibitory concentration (MIC), which was determined in a turbidity-based microdilution assay. ${ }^{31}$ Staphylococcus aureus (S. aureus) ATCC 25923 was grown to the mid-logarithmic phase $\left(\mathrm{OD}_{600}=0.5-0.6\right)$ in Muller-Hinton $(\mathrm{MH})$ broth at pH 7.4 and then diluted to give $\mathrm{OD}_{600}=0.001$, which corresponds to $\sim 2 \times$ $10^{5} \mathrm{cfu} \mathrm{mL}^{-1}$. We mixed $90 \mu \mathrm{L}$ of the prepared bacterial stock suspension with $10 \mu \mathrm{L}$ of solution containing LMI-NNM-1 before and after photoirradiation at $365 \mathrm{~nm}$ for $12 \mathrm{~h}$ in a sterile polypropylene 96-well plate (\#3359, Corning Life Sciences, Corning, NY, USA). The highest concentrations for NNM-1 was $1.82 \mu \mathrm{g} \mathrm{mL}{ }^{-1}$, and the polymer was serially diluted two-fold. The $\mathrm{OD}_{600}$ of each well was measured after incubation at $37^{\circ} \mathrm{C}$ for 18 hours, and any increase in turbidity was considered to be due to $S$. aureus growth. The minimum concentration of NNM-1 or 1 that completely inhibited the growth of $S$. aureus was defined as the MIC.

\section{Conflicts of interest}

There are no conflicts to declare.

\section{Acknowledgements}

This work was supported by a JSPS KAKENHI Grant-in-Aid for Scientific Research (B) (Grant No. JP16H04133) and a Grant-inAid for Challenging Exploratory Research (Grant No. JP16K13982). We thank Sarah Dodds, PhD, from Edanz Group (www.edanzediting.com/ac) for editing a draft of this manuscript.

\section{Notes and references}

1 Y. Malam, M. Loizidou and A. M. Seifalian, Trends Pharmacol. Sci., 2009, 30, 592-599.

2 W. T. Al-Jamal and K. Kostarelos, Acc. Chem. Res., 2011, 44, 1094-1104.

3 T. M. Allen and P. R. Cullis, Adv. Drug Delivery Rev., 2013, 65, 36-48.

4 R. van der Meel, M. Fens, P. Vader, W. W. van Solinge, O. Eniola-Adefeso and R. M. Schiffelers, J. Controlled Release, 2014, 195, 72-85.

5 B. S. Pattni, V. V. Chupin and V. P. Torchilin, Chem. Rev., 2015, 115, 10938-10966.

6 S. Bibi, E. Lattmann, A. R. Mohammed and Y. Perrie, J. Microencapsulation, 2012, 29, 262-276.

7 J. O. Eloy, M. C. D. Souza, R. Petrilli, J. P. A. Barcellos, R. J. Lee and J. M. Marchetti, Colloids Surf., B, 2014, 123, 345-363.

8 K. A. Carter, S. Shao, M. I. Hoopes, D. Luo, B. Ahsan, V. M. Grigoryants, W. Song, H. Huang, G. Zhang, R. K. Pandey, J. Geng, B. A. Pfeifer, C. P. Scholes, J. Ortega, M. Karttunen and J. F. Lovell, Nat. Commun., 2014, 5, 3546.

9 S. Ghosh, R. Qi, K. A. Carter, G. Zhang, B. A. Pfeifer and J. F. Lovell, Biochem. Eng. J., 2019, 141, 43-48.

10 M. Mathiyazhakan, C. Wiraja and C. Xu, Nano-Micro Lett., 2018, 10, 10.

11 B. I. Escher and R. P. Schwarzenbach, Environ. Sci. Technol., 1996, 30, 260-270.

12 Y. Katz and J. M. Diamond, J. Membr. Biol., 1974, 17, 69-86.

13 The values of $\log P_{o w}$ can be calculated using several software packages. The value for NNM-1 was calculated using Advanced Chemistry Development Software V11.02, ACD/Labs.

14 A. Ikeda, K. Ashizawa, Y. Tsuchiya, M. Ueda and K. Sugikawa, RSC Adv., 2016, 6, 78505-78513.

15 R. Shimokawa, M. Ueda, K. Sugikawa and A. Ikeda, J. Photochem. Photobiol., B, 2018, 185, 235-240.

16 W. A. Velema, J. P. van der Berg, W. Szymanski, A. J. M. Driessen and B. L. Feringa, ACS Chem. Biol., 2014, 9, 1969-1974.

17 A. I. Kallenberg, F. van Rantwijk and R. A. Sheldon, Adv. Synth. Catal., 2005, 347, 905-926.

18 G. Gerebtzoff and A. Seelig, J. Chem. Inf. Model., 2006, 46, 2638-2650.

19 F. Kienzle, Helv. Chim. Acta, 1980, 63, 2364-2369.

20 R. A. Moss and X. Fu, Org. Lett., 2004, 6, 3353-3356. 
21 A. K. Singh and P. K. Khade, Tetrahedron, 2005, 61, 1000710012.

22 S. Arrowood, A. M. Hoyt Jr and M. J. Sepaniak, J. Chromatogr., 1992, 583, 105-110.

23 A. D. Bangham, Prog. Biophys. Mol. Biol., 1968, 18, 29-36.

24 M. Ueda, K. Ashizawa, K. Sugikawa, K. Koumoto, T. Nagasaki and A. Ikeda, Org. Biomol. Chem., 2017, 15, 1565-1569.

25 E. Okamura and M. Nakahara, J. Phys. Chem. B, 1999, 103, 3505-3509.

26 E. Okamura, R. Kakitsubo and M. Nakahara, Langmuir, 1999, 15, 8332-8335.

27 M. Vermathen, P. Vermathen, U. Simonis and P. Bigler, Langmuir, 2008, 24, 12521-12533.
28 M. Marzorati, P. Bigler and M. Vermathen, Biochim. Biophys. Acta, 2011, 1808, 1661-1672.

29 N. Weizenmann, D. Huster and H. A. Scheidt, Biochim. Biophys. Acta, 2011, 1818, 3010-3018.

30 T. Nakaya, Y. Tsuchiya, B. Horiguchi, K. Sugikawa, K. Komaguchi and A. Ikeda, Bull. Chem. Soc. Jpn., 2018, 91, 1337-1342.

31 CLSI, Methods for Dilution Antimicrobial Susceptibility Tests for Bacteria That Grow Aerobically; Approved Standard-Ninth Edition, CLSI document M07-A9, Clinical and Laboratory Standards Institute, Wayne, PA, 2012. 